\title{
Effects of stage of oestrous cycle and progesterone supplementation during culture on maturation of canine oocytes in vitro
}

\author{
L. A. Willingham-Rocky, K. Hinrichs, M. E. Westhusin and D. C. Kraemer \\ Department of Veterinary Physiology and Pharmacology, Texas A\&M University, College of Veterinary \\ Medicine, College Station, Texas 77843-4466, USA
}

The aim of this study was to evaluate the effect of progesterone supplementation and stage of oestrous cycle on in vitro maturation (IVM) of canine oocytes. Oocytes were cultured in medium supplemented with $0,2000,4000$ or $8000 \mathrm{ng}$ progesterone $\mathrm{ml}^{-1}$ (Expt $1 ; n=274$ oocytes) or 0, 20, 200 or $2000 \mathrm{ng}$ progesterone $\mathrm{ml}^{-1}$ (Expt 2; $n=789$ oocytes). In Expt 3, oocytes $(n=1202)$ were cultured in a bi-phasic system of meiotic arrest followed by IVM, both in the presence of $0,20,200$ or $2000 \mathrm{ng}$ progesterone $\mathrm{ml}^{-1}$. Rates of meiotic resumption for Expt 1 ranged from $40.0 \%$ to $58.5 \%$; there were no significant differences among groups. In Expt 2, rate of meiotic resumption was significantly lower in the $2000 \mathrm{ng}$ progesterone $\mathrm{ml}^{-1}$ treatment $(35.5 \%)$ compared with the $200 \mathrm{ng}$ progesterone $\mathrm{ml}^{-1}$ treatment $(54.0 \% ; P<0.05)$. There were no significant differences in rates of maturation to metaphase II among treatments in Expt $1(1.8-8.6 \%)$ or Expt 2 (8.4-14.7\%); however, oocytes collected from ovaries of bitches in oestrus and dioestrus had higher rates of maturation to metaphase II than did oocytes from bitches at pro-oestrus or anoestrus $(P<0.01)$. In Expt 3, no differences were observed in rates of maturation among treatment groups. Rates of maturation to metaphase II of oocytes from bitches in dioestrus were significantly higher than those from bitches in pro-oestrus $(P<0.01)$. These results indicate that supplementation of culture medium with progesterone either during maturation or during meiotic arrest before maturation does not increase the rate of IVM of canine oocytes. However, stage of oestrous cycle is a key factor in the selection criteria for meiotically competent canine oocytes for use in in vitro experiments.

\section{Introduction}

In vitro maturation (IVM) is a powerful technique in the study of oocyte physiology. However, there are relatively few reports on IVM in domestic bitches (Mahi and Yanagimachi, 1976; Yamada et al., 1992, 1993; Nickson et al., 1993; Hewitt and England, 1997; Metcalfe, 1999; Otoi et al., 1999, 2000, 2002; Songsasen et al., 2002). The reported rates of meiotic resumption (maturation beyond the germinal vesicle stage) in oocytes from this species range from $0 \%$ to $58 \%$, and rates of maturation to metaphase Il average $20 \%$ (Farstad, 2000). This inefficient rate of meiotic resumption of canine oocytes is largely due to their unique oestrous cycle stage, but is also hindered by an insufficient IVM medium. Therefore, the lack of an adequate IVM system greatly hinders the production of in vitro-matured oocytes, and subsequent experimentation.

The unique oestrous cycle of bitches further complicates the development of research methods to improve IVM in this species. Canines are considered mono-

Email: Iwillingham@cvm.tamu.edu oestrous, and therefore have an extended period of quiescence of the ovary between fertile periods. The inactivity of ovarian function for such a long time is similar to the onset of puberty upon initiation of oestrus. The physiological signals necessary to stimulate the onset of follicular development and ovulation are similar to those of other mammalian species (that is, surges of $\mathrm{FSH}, \mathrm{LH}$ and oestrogen); however, the timing and frequency of this event is not consistent among all domestic canines. Domestic dogs are not considered to be seasonal breeders, and the time lapse between oestrous cycles varies among different breeds and ages of bitches, depending on management factors and genetic influences (Feldman and Nelson, 1996). Thus, unlike many of the domestic, polyoestrous species, collection of oocytes from canine ovaries obtained at routine ovariohysterectomy are most frequently in the anoestrous or dioestrous stages of the cycle. Thus, the availability of suitable females for recovery of oocytes from ovaries at the pro-oestrous and oestrous stages of the oestrous cycle is more problematic.

In canids, there is a peak of LH concentration approximately 2 days before ovulation and oocytes are ovulated 
1-2 days later. Oocytes of most mammalian species are ovulated at the metaphase II stage of meiosis; however, canid oocytes are ovulated at the germinal vesicle stage and mature to metaphase II in the oviduct (Pearson and Enders, 1943). In addition, in mammalian species, the LH surge induces meiotic resumption of the oocyte before ovulation by a combination of actions: these include phosphorylation of gap junctions among cumulus cells and also between the cumulus cells and the oocyte (Granot and Dekel, 2002), intracellular calcium release within the oocyte (He et al., 1997) and initiation of a cascade of cell signalling pathways, resulting in an increase in active maturation promoting factor (MPF) and mitogen-activated protein kinase (MAPK) (Mattioli and Barboni, 2000). The factors that trigger resumption of meiosis after ovulation in domestic bitches are currently unknown and very limited information is available regarding oocyte cell signalling mechanisms in canids (Krogenæs et al., 1993; Kalab et al., 1997).

Although LH is probably a key signal for maturation of canid oocytes, it either does not evoke the same response as in other mammalian species, or proceeds in a different time frame. Hewitt and England (1999) reported that the addition of both $\mathrm{FSH}$ and $\mathrm{LH}$ to culture medium did not improve the rate of meiotic resumption in domestic canine oocytes, indicating an especially juvenile and incompetent population of oocytes selected for IVM. Unlike oocytes of other species, most immature canid oocytes do not resume meiosis or mature to metaphase II when removed from the follicle and cultured in vitro, regardless of the culture conditions used. Numerous variations in culture conditions and adaptations of the bovine model for in vitro culture have been investigated, including type and concentration of serum, temperature, gas composition, and addition of hormones and growth factors. Although the results of these experiments have yielded beneficial insights into the exploration of IVM of domestic canine oocytes, there has been very little progress in increasing the rates of maturation to metaphase II necessary for the study of oocyte physiology and subsequent development of embryos from other artificial reproductive technologies. This poses a challenge in the understanding of oocyte meiotic resumption in canids and greatly hinders the production of mature oocytes in an in vitro system.

As progesterone production is initiated in the follicle well before ovulation in dogs, it is possible that progesterone contributes to acquisition of meiotic competence or to resumption of meiosis of canine oocytes. Progesterone production by the granulosa cells of the preovulatory follicle increases markedly before ovulation in bitches to concentrations detectable in the peripheral sera on the day before the LH surge. Serum progesterone concentrations continue to increase after ovulation, during the time that the oocytes are completing maturation in the oviduct. The concentration of progesterone found in follicular fluid of canine preovulatory follicles (after the LH surge, and when the blood serum concentration of progesterone is $\geqslant 7 \mathrm{ng} \mathrm{ml}^{-1}$ ) averages about $7700 \mathrm{ng} \mathrm{ml}^{-1}$, whereas the progesterone concentration in bursal fluid collected during the time of ovulation averages about $450 \mathrm{ng}$ $\mathrm{ml}^{-1}$ (Metcalfe, 1999; Willingham-Rocky, 2001). It is possible that the high progesterone concentration within the follicle induces meiotic competence of the oocyte during meiotic arrest, and that the sharp decrease in progesterone exposure at ovulation triggers resumption of meiosis. Metcalfe (1999) speculated that the oviductal concentration of progesterone may be similar to that of the bursal fluid at about the time of ovulation, but this has not been confirmed. No studies have been published evaluating canine oviductal fluid. Only one report is available regarding the effect of progesterone supplementation of IVM medium on rates of maturation of canine oocytes (Hewitt, 1997); supplementation with $1000 \mathrm{ng}$ progesterone $\mathrm{ml}^{-1}$ yielded $10 \%$ meiotic resumption (maturation beyond the germinal vesicle stage), whereas in the control medium, without hormone supplementation, the rate of meiotic resumption was $2 \%$ (Hewitt, 1997). The rate of meiotic resumption in the control group in this study is low in relation to other reports and thus the effect of progesterone is difficult to assess from these data.

The aim of the present study was to evaluate more thoroughly the effect of progesterone supplementation of IVM medium in supporting resumption of meiosis and maturation to metaphase II in canine oocytes, as well as to investigate any effects of stage of oestrous cycle. Maturation was also evaluated in a bi-phasic system in which oocytes were exposed to progesterone during meiotic arrest, followed by IVM in the presence of various concentrations of progesterone. This system was expected to mimic the exposure of oocytes to high progesterone concentrations within the preovulatory follicle, followed by the considerable decrease observed at ovulation, thereby mimicking the environment to which canine oocytes are exposed in vivo.

\section{Materials and Methods}

\section{Collection of oocytes}

Reproductive tracts from normal, client-owned bitches aged $>6$ months were collected after routine ovariohysterectomy at private veterinary clinics and transported to the laboratory within $6 \mathrm{~h}$. A vaginal cytology swab specimen and venous blood sample were collected from each bitch after induction of anaesthesia for the surgery. Stage of oestrous cycle was evaluated for each bitch by assessment of vaginal cytology (Feldman and Nelson, 1996), blood serum progesterone concentrations (Ovucheck Premate ${ }^{\circledR}$; Camelot Farms, College Station, TX) and ovarian morphology. In brief, bitches were 
considered to be in anoestrus when vaginal cytology revealed parabasal cells on vaginal swabs, and progesterone concentrations were less than the kit standard for low progesterone. Bitches were classified as at the pro-oestrous stage if intermediate epithelial cells, some superficial cells and red blood cells were present on the vaginal swab, and progesterone concentrations were less than the kit standard for low progesterone. Bitches with superficial cells present on the vaginal swabs and progesterone concentrations between the kit standard low and high value were considered to be in oestrus, and bitches with parabasal cells on the vaginal swab and progesterone concentrations greater than the high progesterone kit standard were considered to be in dioestrus (Feldman and Nelson, 1996). Morphological criteria for assessing stage of oestrous cycle on the ovaries were followed as described by Otoi et al. (2002).

After removal, the reproductive tracts were placed immediately into physiological saline solution (PSS) at $37^{\circ} \mathrm{C}$ and transported back to the laboratory for processing. The ovaries were removed and washed free of blood in fresh PSS, and then repeatedly cut with a no. 10 scalpel blade at room temperature in bench medium (M-199 with Hank's salts and 25 mmol Hepes $\mathrm{I}^{-1}$; Gibco; Grand Island, NY), supplemented with $1 \%$ fetal calf serum (FCS; Hyclone, Logan, UT) and $10000 \mathrm{U}$ penicillin $\mathrm{G}$ sodium $\mathrm{ml}^{-1}$ and $10000 \mu \mathrm{g}$ streptomycin sulphate (P/S) $\mathrm{ml}^{-1}$ (Gibco). Only oocytes with more than two layers of cumulus and a homogenous cytoplasm $>100 \mu \mathrm{m}$ in diameter were selected for use (Hewitt and England, 1997; Otoi et al., 2000). Cumulus-oocyte complexes were washed three times in bench medium before transfer to maturation medium.

\section{Maturation of oocytes}

Base maturation medium was modified from that described by Srsen et al. (1998); it consisted of medium M-199 with Earle's salts (Gibco), supplemented with $2.92 \mathrm{mmol}^{\text {lactic acid I }}{ }^{-1}$ (Sigma, St Louis, MO), $2.0 \mathrm{mmol}^{2}$ sodium pyruvate $\mathrm{I}^{-1}$ (Sigma), $4.43 \mathrm{mmol}$ Hepes $\mathrm{I}^{-1}$ (Sigma), 10\% heat-inactivated bitch serum and $1 \%(\mathrm{v} / \mathrm{v}) \mathrm{P} / \mathrm{S}$.

Water-soluble progesterone (cat. no. P7556; Sigma) was added to maturation medium and its influence was assessed in three different experiments. In Expt 1, medium containing $10 \%$ bitch serum was supplemented with progesterone at concentrations of 0 (control), 2000, 4000 and $8000 \mathrm{ng} \mathrm{ml}^{-1}$. Oocytes from all stages of the oestrous cycle were pooled in Expt 1. In Expt 2, medium containing $10 \%$ bitch serum was supplemented with 0 (control), 20, 200 or $2000 \mathrm{ng}$ progesterone $\mathrm{ml}^{-1}$; within progesterone treatments, oocytes were grouped by stage of oestrous cycle.

In Expt 3,10\% of the total number of oocytes selected was evaluated for meiotic status immediately after collec- tion to serve as a $0 \mathrm{~h}$ control for proportion of germinal vesicle stage oocytes. The remaining oocytes were cultured in maturation medium with $10 \%$ bitch serum, supplemented with either $2000 \mathrm{ng}$ progesterone $\mathrm{ml}^{-1}$ and $1.0 \mathrm{mmol}$ dibutyryl cyclic adenosine monophosphate $\mathrm{I}^{-1}$ (dbcAMP; Sigma) to maintain meiotic arrest (designated A2000) or no progesterone and $1.0 \mathrm{mmol}$ dbcAMP $\mathrm{I}^{-1}$ (designated $\mathrm{A} 0$ ) for $20 \mathrm{~h}$ in $5 \% \mathrm{CO}_{2}$ and air at $39^{\circ} \mathrm{C}$. The concentration chosen for dbcAMP was selected on the basis of experiments involving meiotic inhibition of canine oocytes in response to different concentrations of dbcAMP in our laboratory (Hanna et al., 2001). At the end of the $20 \mathrm{~h}$ period, $10 \%$ of the oocytes were removed from each group and stained to confirm germinal vesicle status. The remainder of the oocytes from each meiotic arrest group was washed five times in bench medium (dbcAMP-free) and then divided into one of four treatment groups for culture in medium containing $0,20,200$ or $2000 \mathrm{ng}$ progesterone $\mathrm{ml}^{-1}$ (designated P0, P20, P200 and P2000, respectively). The oocytes were cultured in four-well dishes (cat. no. 176740; Nunc, Roskilde) with medium at a ratio of $10 \mu \mathrm{l}$ per oocyte for $48 \mathrm{~h}$ in an atmosphere of $5 \% \mathrm{CO}_{2}$ in humidified air at $39^{\circ} \mathrm{C}$. The studies comprising Expt 3 were performed individually for the three progesterone concentrations used for maturation (that is, P20, P200 or P2000), with a P0 (no progesterone during maturation) control run during each study. This is reflected in the total number of oocytes given in the combined data for this experiment.

\section{Removal of cumulus cells and assessment of meiotic stage}

At the end of the culture period, oocytes were completely denuded via gentle pipetting with a fine bore glass pipette in a 33\% (v/v) trypsin solution (Sigma) in bench medium. The oocytes were fixed in a $3.7 \%$ $(\mathrm{v} / \mathrm{v})$ formaldehyde-Triton-X100 (Sigma) solution for 15 min, washed in a solution of DPBS (Gibco) containing $3 \mathrm{mg}$ polyvinylpropinal (PVP) $\mathrm{ml}^{-1}$ (Sigma) for an additional $15 \mathrm{~min}$, and mounted on a slide with an overlay of $1.9 \mu \mathrm{mol}$ Hoechst $33342 \mathrm{I}^{-1}$ (Sigma) in glycerol (Sigma). The oocytes were evaluated under fluorescence microscopy with UV light to determine the stage of meiosis.

Oocytes with an intact germinal vesicle containing fibrillar chromatin were considered to be in the germinal vesicle stage. Oocytes with an organization of chromatin into chromosomes were considered to be in germinal vesicle breakdown (resuming meiosis). Other categories were metaphase I, metaphase II and degenerating (chromatin in dense or hair-like clusters or spread throughout the cell). Only non-degenerating oocytes were used for statistical analysis in this study due to the large population of incompetent oocytes (Hay et al., 1994; Farstad et al., 2001) recovered from canine ovaries. 
Table 1. Meiotic maturation of canine oocytes in in vitro maturation medium supplemented with 2000, 4000 or 8000 ng progesterone $\mathrm{ml}^{-1}($ Expt 1)

\begin{tabular}{lccccccc}
\hline $\begin{array}{l}\text { Treatment } \\
\left(\text { ng progesterone } \mathrm{ml}^{-1} \text { ) }\right.\end{array}$ & $\begin{array}{c}\text { Number of oocytes } \\
\text { collected }\end{array}$ & $\begin{array}{c}\text { Degenerating } \\
(\%)\end{array}$ & $\begin{array}{c}\text { Viable } \\
\text { oocytes* }\end{array}$ & $\begin{array}{c}\text { Germinal } \\
\text { vesicle (\%) }\end{array}$ & $\begin{array}{c}\text { GVBD- } \\
\text { metaphase I (\%) }\end{array}$ & $\begin{array}{c}\text { Metaphase II } \\
(\%)\end{array}$ & $\begin{array}{c}\text { \% Meiotic resumption } \\
(\text { GVBD-metaphase II) }\end{array}$ \\
\hline 2000 & 68 & $10(14.7)$ & 58 & $30(51.7)$ & $23(39.7)$ & $5(8.6)$ & $28(48.3)$ \\
4000 & 68 & $13(19.1)$ & 55 & $33(60.0)$ & $21(38.2)$ & $1(1.8)$ & $22(40.0)$ \\
8000 & 70 & $17(24.3)$ & 53 & $29(54.7)$ & $23(43.4)$ & $1(1.9)$ & $24(45.3)$ \\
Control & 68 & $15(22.1)$ & 53 & $22(41.5)$ & $30(56.6)$ & $1(1.9)$ & $31(58.5)$ \\
Total & 274 & $55(20.0)$ & 219 & - & - & - & - \\
\hline
\end{tabular}

*Total oocytes minus degenerating oocytes.

GVBD: germinal vesicle breakdown.

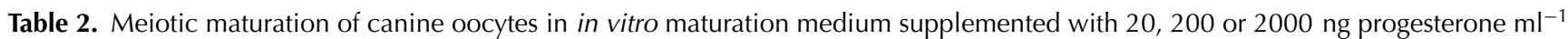
(Expt 2)

\begin{tabular}{lccccccc}
\hline $\begin{array}{l}\text { Treatment } \\
\left(\text { ng progesterone } \mathrm{ml}^{-1} \text { ) }\right.\end{array}$ & $\begin{array}{c}\text { Number of oocytes } \\
\text { collected }\end{array}$ & $\begin{array}{c}\text { Degenerating } \\
(\%)\end{array}$ & $\begin{array}{c}\text { Viable } \\
\text { oocytes* }^{*}\end{array}$ & $\begin{array}{c}\text { Germinal } \\
\text { vesicle (\%) }\end{array}$ & $\begin{array}{c}\text { GVBD- } \\
\text { metaphase I (\%) }\end{array}$ & $\begin{array}{c}\text { Metaphase II } \\
(\%)\end{array}$ & $\begin{array}{c}\text { \% Meiotic resumption } \\
(\text { GVBD-metaphase II) }\end{array}$ \\
\hline 20 & 196 & $53(27.0)$ & 143 & $76(53.1)^{\mathrm{ab}}$ & $55(38.5)^{\mathrm{a}}$ & $12(8.4)$ & $67(46.9)^{\mathrm{ab}}$ \\
200 & 201 & $51(25.4)$ & 150 & $69(46.0)^{\mathrm{a}}$ & $65(43.3)^{\mathrm{a}}$ & $16(10.7)$ & $81(54.0)^{\mathrm{a}}$ \\
2000 & 196 & $55(28.1)$ & 141 & $91(64.5)^{\mathrm{bc}}$ & $36(25.5)^{\mathrm{bc}}$ & $14(9.9)$ & $50(35.5)^{\mathrm{b}}$ \\
Control & 196 & $67(34.2)$ & 129 & $67(51.9)^{\mathrm{a}}$ & $43(33.3)^{\mathrm{a}}$ & $19(14.7)$ & $62(48.1)^{\mathrm{a}}$ \\
Total & 789 & $226(28.6)$ & 563 & - & - & - & - \\
\hline
\end{tabular}

*Total oocytes minus degenerating oocytes.

GVBD: germinal vesicle breakdown.

${ }^{a-c}$ Different letters in the same column indicate significant differences $(P<0.05)$.

\section{Statistical analysis}

Each experiment was repeated at least three times. Effect of progesterone concentration in IVM medium on oocyte maturation was evaluated using chi-squared analysis and Fisher's exact test was used when a value of $<0.05$ was expected for any parameter. All statistical analyses were performed using either Stat View for Windows version 5.0 (SAS Institute, Inc., San Francisco, CA) or Microsoft Excel 97 (Microsoft Corporation) or both.

\section{Results}

\section{Experiment 1}

A total of 274 oocytes was selected and pooled from ten bitches. Bitches were in anoestrus $(n=2)$, prooestrus $(n=2)$, oestrus $(n=1)$ or dioestrus $(n=5)$. After $48 \mathrm{~h}$ of culture, $55(20.0 \%)$ of the oocytes were degenerating. Of the 219 remaining oocytes, rates of meiotic resumption for the control, 2000, 4000 and $8000 \mathrm{ng}$ progesterone $\mathrm{ml}^{-1}$ treatment groups were 58.5, 48.3, 40.0 and $45.3 \%$, respectively. Rates of maturation to metaphase II were $1.9,8.6,1.8$ and $1.9 \%$, respectively (Table 1). There were no significant differences in rates of meiotic resumption or maturation to metaphase II among treatment groups.

\section{Experiment 2}

On the basis of the lack of significant differences found in Expt 1, intermediate concentrations (0, 20, 200 and $2000 \mathrm{ng} \mathrm{ml}^{-1}$ ) of progesterone were selected for evaluation in Expt 2. In addition, oocytes were classified and grouped by the stage of oestrous cycle of the bitch to determine its effect on rates of maturation.

A total of 789 oocytes was used from 28 bitches. Bitches were at the anoestrous $(n=6)$, pro-oestrous $(n=10)$, oestrous $(n=1)$ or dioestrous $(n=11)$ stage of the oestrous cycle. The rates of maturation for each progesterone treatment are shown (Table 2). After $48 \mathrm{~h}$ of culture, $226(28.6 \%)$ oocytes were considered to be degenerating. There were no significant differences in the rate of degeneration among progesterone treatment groups. Of the remaining 563 oocytes, rates of meiotic resumption for $0,20,200$ or 2000 ng progesterone $\mathrm{ml}^{-1}$ treatments were $48.1,46.9,54.0$ and $35.5 \%$, respectively. Oocytes in the $2000 \mathrm{ng}$ progesterone $\mathrm{ml}^{-1}$ group had a significantly lower rate of resumption of meiosis than did oocytes in the 200 ng progesterone $\mathrm{ml}^{-1}$ group. Rates of maturation to metaphase II were $14.7,8.4,10.7$ and $9.9 \%$, respectively. There were no significant differences in rate of maturation to metaphase II among progesterone treatment groups.

Within each stage of the oestrous cycle, there were no significant differences in resumption of meiosis 
or maturation to metaphase II among progesterone treatments, so data for treatments were combined to evaluate the effect of stage of oestrous cycle (Fig. 1). Stage of oestrous cycle had a significant effect on maturation to metaphase II $(P<0.01)$. Rates of maturation of oocytes from bitches in oestrus and dioestrus were not significantly different; similarly, the rates of maturation for oocytes from bitches in anoestrus or pro-oestrus were not significantly different from one another. The rates of maturation to metaphase II for oocytes from bitches in oestrus and dioestrus were significantly higher than the rate of maturation for oocytes from bitches in anoestrus or pro-oestrus $(P<0.01)$.

\section{Experiment 3}

A total of 581 oocytes was used from 16 bitches in dioestrus and 621 oocytes were used from 21 bitches in pro-oestrus. Oocytes were collected as described previously and cultured separately according to stage of oestrous cycle. At the $0 \mathrm{~h}$ control, $20 \mathrm{~h}$ A0 and 20 h A2000 checkpoints, 96, 100, and 95\% of viable oocytes collected from dioestrous bitches, and 100, 100 and $100 \%$, respectively, of viable oocytes collected from bitches in pro-oestrus from the combined treatment groups were at the germinal vesicle stage of meiosis.

Of the 581 oocytes collected from dioestrous ovaries, $268(46 \%)$ were considered as degenerating at the end of the culture periods. From the remaining 221 viable (and non-checkpoint control groups) oocytes, 76 (34\%) progressed beyond the germinal vesicle stage, and $20(9 \%)$ matured to metaphase II in the combined treatment groups during the culture period. However, comparison between treatment groups revealed that meiotic resumption was significantly higher in the A0P2000 group than in the A0-P0 and A0-P20 groups $(P<0.05)$. In addition, the A0-P2000 group showed significantly less oocyte degeneration $(P<0.05)$ than did the A0-P20 group. There were no significant differences in maturation to metaphase II among or between treatments within the dioestrous group (Table 3).

Of the 621 oocytes collected from pro-oestrous ovaries, $250(40.26 \%)$ were considered as degenerating at the end of the culture period. Of the remaining 270 viable (and non-checkpoint control groups) oocytes, $102(38 \%)$ progressed beyond the germinal vesicle stage and eight (3\%) matured to metaphase II in the combined treatment groups during the culture period. Meiotic resumption was significantly higher in the A0P20 treatment group than in the A0-P2000 treatment group $(P<0.05)$. There were no significant differences in maturation to metaphase II among treatments within the pro-oestrus group (Table 4).

As there were no differences in maturation to the metaphase II stage among progesterone treatment groups for oocytes obtained from ovaries of either dioestrous or proestrous bitches, the treatment groups were combined

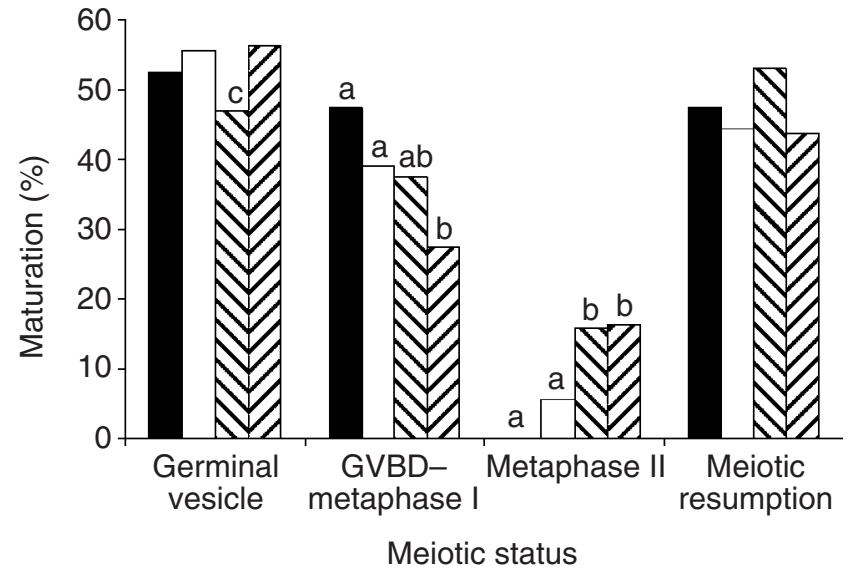

Fig. 1. Effect of stage of oestrous cycle on meiotic maturation of canine oocytes after $48 \mathrm{~h}$ in vitro maturation (Expt 2). $\mathbf{\square}$ : anoestrus; $\square$ : pro-oestrus; $\nabla$ : oestrus; $\square$ : dioestrus. GVBD: germinal vesicle breakdown. Oocytes obtained from bitches in oestrus or dioestrus are more competent to undergo maturation to metaphase II. ${ }^{\mathrm{a}-\mathrm{b}}$ Different letters indicate significant differences in the same meiotic status group $(P<0.05)$.

to assess differences between the two stages of the oestrous cycle. Oocytes from dioestrous bitches had a significantly higher rate of maturation to the metaphase II stage $(9.0 \%)$ than did oocytes from pro-oestrous bitches $(3 \% ; P<0.01)$.

\section{Discussion}

In the present study, addition of progesterone to in vitro culture medium, either during maturation or during meiotic arrest before maturation, did not increase the proportion of canine oocytes progressing to the metaphase II stage. The concentrations of progesterone used in Expt 1 were intended to mimic follicular progesterone concentrations and to provide a starting point for progesterone supplementation experiments. As there was a slight, but insignificant, increase in maturation to the metaphase II stage in the 2000 ng progesterone $\mathrm{ml}^{-1}$ group in this experiment, intermediate progesterone concentrations were examined in Expt 2. It was found that $200 \mathrm{ng}$ progesterone $\mathrm{ml}^{-1}$ supported the highest rate of resumption of meiosis, and that this was significantly higher than that found in oocytes in the $2000 \mathrm{ng}$ progesterone $\mathrm{ml}^{-1}$ treatment; however, this increased resumption of meiosis was not reflected in a higher rate of maturation to the metaphase II stage. The highest rate of maturation to the metaphase II stage was observed in oocytes in the control treatments.

Stage of oestrous cycle had a significant effect on the proportion of oocytes maturing to the metaphase II stage in culture. The increased meiotic competence of oocytes from bitches in oestrus and dioestrus is a significant finding that may help in designing future approaches to 
Table 3. Meiotic maturation of canine oocytes obtained from bitches in dioestrus and cultured in vitro in medium supplemented with progesterone using a bi-phasic system (Expt 3)

\begin{tabular}{|c|c|c|c|c|c|c|c|}
\hline $\begin{array}{l}\text { Treatment } \\
\left(\text { ng progesterone } \mathrm{ml}^{-1} \text { ) }\right.\end{array}$ & $\begin{array}{c}\text { Number of oocytes } \\
\text { collected }\end{array}$ & $\begin{array}{c}\text { Degenerating } \\
(\%)\end{array}$ & $\begin{array}{c}\text { Viable } \\
\text { oocytes* }\end{array}$ & $\begin{array}{c}\text { Germinal } \\
\text { vesicle }(\%)\end{array}$ & $\begin{array}{c}\text { GVBD- } \\
\text { metaphase I (\%) }\end{array}$ & $\begin{array}{c}\text { Metaphase II } \\
(\%)\end{array}$ & $\begin{array}{l}\text { \% Meiotic resumption } \\
\text { (GVBD-metaphase II) }\end{array}$ \\
\hline \multicolumn{8}{|l|}{ Controls } \\
\hline $0 \mathrm{~h}$ control & 56 & $8(14)$ & $48(86)$ & $46(96)$ & $2(4.2)$ & 0 & $2(4.2)$ \\
\hline $20 \mathrm{~h} \mathrm{A0}$ & 26 & $4(15)$ & $22(85)$ & $22(100)$ & 0 & 0 & 0 \\
\hline 20 h A2000 & 26 & $4(15)$ & $22(85)$ & $21(95)$ & $1(4.5)$ & 0 & $1(4.5)$ \\
\hline \multicolumn{8}{|l|}{ Arrest treatment $\mathrm{A} 0$} \\
\hline A0-PO & 118 & $61(52)^{a b}$ & $57(48)^{a b}$ & $43(75)^{\mathrm{a}}$ & $9(16)^{\mathrm{a}}$ & $5(9)$ & $14(25)^{\mathrm{a}}$ \\
\hline A0-P20 & 33 & $22(67)^{\mathrm{a}}$ & $11(33)^{\mathrm{a}}$ & $9(82)^{\mathrm{a}}$ & $2(18)^{\mathrm{ab}}$ & 0 & $2(18)^{\mathrm{a}}$ \\
\hline A0-P200 & 52 & $27(52)^{a b}$ & $25(48)^{a b}$ & $17(68)^{\mathrm{ab}}$ & $6(24)^{a b}$ & $2(8)$ & $8(32)^{a b}$ \\
\hline A0-P2000 & 34 & $12(35)^{b}$ & $22(65)^{b}$ & $9(41)^{b}$ & $8(36)^{b}$ & $5(23)$ & $13(59)^{b}$ \\
\hline \multicolumn{8}{|l|}{ Arrest treatment A2000 } \\
\hline A2000-P0 & 118 & $59(50)^{\mathrm{a}}$ & $59(50)^{\mathrm{a}}$ & $37(63)$ & $19(32)$ & $3(5)$ & $22(37)$ \\
\hline A2000-P20 & 32 & $23(72)^{b}$ & $9(28)^{b}$ & $8(89)$ & $1(11)$ & 0 & $1(11)$ \\
\hline A2000-P200 & 53 & $29(55)^{a b}$ & $24(45)^{a b}$ & $14(58)$ & $7(29)$ & $3(13)$ & $10(42)$ \\
\hline A2000-P2000 & 33 & $19(58)^{a b}$ & $14(42)^{a b}$ & $8(57)$ & $4(29)$ & $2(14)$ & $6(43)$ \\
\hline
\end{tabular}

GVBD: germinal vesicle breakdown.

A0: medium containing $1 \mathrm{mmol}$ dibutyryl cyclic adenosine monophosphate (dbcAMP) $\mathrm{I}^{-1}$ and no progesterone; A2000: medium containing $1 \mathrm{mmol} \mathrm{dbcAMP} \mathrm{I}^{-1}$ and $2000 \mathrm{ng}$ progesterone $\mathrm{ml}^{-1}$; P0: medium containing no progesterone or dbcAMP; P20, P200 or P2000: medium containing 20, 200 or $2000 \mathrm{ng}$ progesterone $\mathrm{ml}^{-1}$, respectively, and no dbcAMP.

*Total oocytes minus degenerating oocytes.

${ }^{\mathrm{ab}}$ Different letters within a column indicate significant differences within a treatment group $(P<0.05)$.

Table 4. Meiotic maturation of canine oocytes obtained from bitches in pro-oestrus and cultured in vitro in medium supplemented with progesterone using a bi-phasic system (Expt 3)

\begin{tabular}{|c|c|c|c|c|c|c|c|}
\hline $\begin{array}{l}\text { Treatment } \\
\left(\text { ng progesterone } \mathrm{ml}^{-1} \text { ) }\right.\end{array}$ & $\begin{array}{l}\text { Number of oocytes } \\
\text { collected }\end{array}$ & $\begin{array}{c}\text { Degenerating } \\
(\%)\end{array}$ & $\begin{array}{c}\text { Viable } \\
\text { oocytes* }\end{array}$ & $\begin{array}{c}\text { Germinal } \\
\text { vesicle }(\%)\end{array}$ & $\begin{array}{c}\text { GVBD- } \\
\text { metaphase I (\%) }\end{array}$ & $\begin{array}{c}\text { Metaphase II } \\
(\%)\end{array}$ & $\begin{array}{l}\text { \% Meiotic resumption } \\
\text { (GVBD-metaphase II) }\end{array}$ \\
\hline \multicolumn{8}{|l|}{ Controls } \\
\hline $0 \mathrm{~h}$ control & 61 & $9(15)$ & $52(85)$ & $52(100)$ & 0 & 0 & 0 \\
\hline $20 \mathrm{~h} \mathrm{A0}$ & 27 & $2(7)$ & $25(93)$ & $25(100)$ & 0 & 0 & 0 \\
\hline 20 h A2000 & 27 & $3(11)$ & $24(89)$ & $24(100)$ & 0 & 0 & 0 \\
\hline \multicolumn{8}{|l|}{ Arrest treatment $\mathrm{A} 0$} \\
\hline $\mathrm{A} 0-\mathrm{PO}$ & 127 & $50(39)^{a x}$ & $77(51)^{\mathrm{a}}$ & $50(65)^{a b}$ & $24(31)^{\mathrm{ab}}$ & $3(4)$ & $27(35)^{a b}$ \\
\hline A0-P20 & 43 & $12(28)^{\mathrm{ax}}$ & $31(72)^{a}$ & $15(48)^{\mathrm{a}}$ & $15(48)^{\mathrm{a}}$ & $1(3)$ & $16(51)^{\mathrm{a}}$ \\
\hline A0-P200 & 36 & $26(72)^{b x}$ & $10(28)^{b}$ & $7(70)^{\mathrm{ab}}$ & $3(30)^{\mathrm{ab}}$ & 0 & $3(30)^{\mathrm{ab}}$ \\
\hline A0-P2000 & 49 & $23(47)^{\mathrm{a}}$ & $26(53)^{\mathrm{a}}$ & $20(77)^{b}$ & $5(19)^{b}$ & $1(4)$ & $6(23)^{b}$ \\
\hline \multicolumn{8}{|l|}{ Arrest treatment A2000 } \\
\hline A2000-P0 & 125 & $65(52)^{y}$ & $60(48)$ & $34(57)$ & $24(40)$ & $2(3)$ & $26(43)$ \\
\hline A2000-P20 & 42 & $22(52)^{y}$ & $20(48)$ & $12(60)$ & $7(35)$ & $1(5)$ & $8(40)$ \\
\hline A2000-P200 & 34 & $15(44)^{y}$ & $19(56)$ & $13(68)$ & $6(32)$ & 0 & $6(32)$ \\
\hline A2000-P2000 & 50 & $23(46)$ & $27(54)$ & $17(63)$ & $10(37)$ & 0 & $10(37)$ \\
\hline
\end{tabular}

GVBD: germinal vesicle breakdown.

A0: medium containing $1 \mathrm{mmol}$ dibutyryl cyclic adenosine monophosphate (dbcAMP) $\mathrm{I}^{-1}$ and no progesterone; A2000: medium containing $1 \mathrm{mmol}$ dbcAMP I${ }^{-1}$ and $2000 \mathrm{ng}$ progesterone $\mathrm{ml}^{-1}$; P0: medium containing no progesterone or dbcAMP; P20, P200 or P2000: medium containing 20, 200 or 2000 ng progesterone $\mathrm{ml}^{-1}$, respectively, and no dbcAMP.

*Total oocytes minus degenerating oocytes.

${ }^{a b}$ Letters indicate significant differences within treatment groups; ${ }^{x y}$ letters indicate significant differences between treatment groups $(P<0.05)$.

canine IVM. Dominant preovulatory follicles are found on canine ovaries only during late pro-oestrus and early oestrus, because ovulation occurs in the first few days of oestrus. Therefore, most oocytes that were recovered and matured in vitro in the oestrous group, and all oocytes from the dioestrous group, were not from preovulatory follicles, but were most probably from either subordinate or atretic follicles. It is notable that oocytes recovered during a time when dominant preovulatory follicles are present (pro-oestrus) had a significantly lower rate of 
maturation to the metaphase II stage than did oocytes from ovaries in oestrus or dioestrus. As they have not yet been selected for follicular recruitment, most of the oocytes obtained from late oestrous or dioestrous bitches have probably not been subjected to extremely high progesterone concentrations within the follicle, as their follicles are unlikely to be steroidogenically competent or to respond appropriately to LH stimulation. However, the follicles would be exposed to the concentrations of progesterone in the circulating blood (from $2 \mathrm{ng} \mathrm{ml}^{-1}$ to $>30 \mathrm{ng} \mathrm{m}^{-1}$ ). In addition, these follicles would be expected to be in early to mid-atresia. Increased rates of maturation have been reported in oocytes from follicles in early to mid-atresia in horses (Hinrichs and Williams, 1997) and in early atresia in cows (Blondin and Sirard, 1995). This is attributed to the atretic follicle losing its ability to inhibit acquisition of meiotic competence of the enclosed oocyte. A similar situation may be occurring in bitches; oocytes from viable follicles (prooestrus) may not yet have gained meiotic competence, and oocytes from late atretic follicles (anoestrus) may be degenerating; therefore, these oocytes have lower rates of maturation than do those from early to mid-atretic follicles (oestrus and dioestrus).

Addition of high concentrations of steroid hormones, such as testosterone, to IVM medium for pigs and mice, and progesterone, pregnenolone, androstenedione and oestradiol for mice (Smith and Tenney, 1980; Aktas et al., 1995), has been linked to meiotic arrest in culture. We postulated that canine oocytes might be affected by high follicular progesterone concentrations in a similar fashion in vivo, aiding arrest at the germinal vesicle stage within the follicle until the time of ovulation. As release from high progesterone concentrations at ovulation is followed by a resumption of meiosis and progression to metaphase Il within the oviductal environment, it seemed logical that this decrease in progesterone concentration might be a trigger for the onset of maturation. The aim of Expt 3 was to evaluate the effect of changing concentrations of progesterone (from high to low and vice versa) on IVM of canine oocytes. However, the culture of canine oocytes in a bi-phasic manner, with various concentrations of progesterone, had no effect on the rate of maturation to the metaphase II stage. Although the specific treatments used in the present study did not show an effect, this approach still warrants further work; for example, gonadotrophins were not included in the maturation medium in the present study because results from preliminary experiments and previously published results (Hewitt and England, 1999) indicated no beneficial effect of supplementation. It is possible that interactions among gonadotrophins, progesterone concentrations and factors maintaining meiotic arrest may work together to induce meiotic competence within canine oocytes.

According to Hyttel et al. (1990), in vivo-ovulated oocytes obtained from blue fox begin initial stages of meiotic resumption at 1-2 days after the $\mathrm{LH}$ surge (just before ovulation). This conclusion was ascertained by monitoring the migratory pattern of the nucleus and breakdown of the germinal vesicle by electron microscopy. Oocytes were collected from either preovulatory follicles (before and after LH peak), or by uterine flushing of vixens at various stages of oestrus. The patterns of nuclear migration and oocyte maturation of blue fox oocytes were consistent with those for other mammalian species (Hyttel et al., 1990), but have not been reported in domestic canines.

The rates of maturation to metaphase II achieved in the present study $(1.9-14.7 \%)$ are consistent with those that have been reported previously for canine IVM in general (Farstad, 2000). Understanding the mechanisms of oocyte maturation in this species, which possesses the same components as other mammalian species (FSH and $\mathrm{LH}$ surges, follicular oestradiol production changing to progesterone production, $\mathrm{LH}$-induced ovulation), but responds to them so differently, continues to present a scientific challenge.

The authors gratefully acknowledge all members of the Reproductive Sciences Laboratory at Texas A\&M University for their guidance and support of this research. This research was funded by Bio-Arts Research Corporation.

\section{References}

Aktas H, Wheeler MB, First NL and Leibfried-Rutledge ML (1995) Maintenance of meiotic arrest by increasing [CAMP] may have physiological relevance in bovine oocytes Journal of Reproduction and Fertility 105 237-245

Blondin P and Sirard MA (1995) Oocyte and follicular morphology as determining characteristics for developmental competence in bovine oocytes Molecular Reproduction and Development 41 54-62

Farstad W (2000) Assisted reproductive technology in canid species Theriogenology 53 175-186

Farstad W, Hyttell P, Hafne AL and Nielsen J (2001) Maturation and fertilization of blue fox (Alopex lagopus) oocytes in vitro. Journal of Reproduction and Fertility Supplement 57 161-165

Feldman E and Nelson R (1996) Canine female reproduction. In Canine and Feline Endocrinology and Reproduction pp 526-546. WB Saunders Company, Philadelphia

Granot I and Dekel N (2002) The ovarian gap junction protein connexin 43: regulation by gonadotrophins Trends in Endocrinology and Metabolism 13 310-313

Hanna CB, Long CR, Westhusin ME and Kraemer DC (2001) Arresting canine oocytes in the germinal vesicle phase of meiosis I Theriogenology 57722

Hay M, King WA, Gartley CJ and Goodrowe KL (1994) Influence of spermatozoa on in vitro nuclear maturation of canine ova Biology of Reproduction 450 Supplement 1362

He CL, Damiani P, Parys JB and Fissore RA (1997) Calcium, calcium release receptors, and meiotic resumption in bovine oocytes Biology of Reproduction 57 1245-1255

Hewitt DA (1997) Oocyte Maturation and Fertilization in the Bitch; the Use of In Vitro Culture PhD Thesis, University of London

Hewitt DA and England GCW (1997) The effect of oocyte size and bitch age upon oocyte nuclear maturation in vitro. Theriogenology 49 957-996

Hewitt DA and England GCW (1999) Influence of gonadotropin supplementation on the in vitro maturation of bitch oocytes Veterinary Record 144 237-239 
Hinrichs K and Williams KA (1997) Relationships among oocyte-cumulus morphology, follicular atresia and oocyte meiotic competence in the horse Biology of Reproduction 57 377-384

Hyttel P, Farstad W, Mondain-Monval M, Lajord KB and Smith AJ (1990) Structural aspects of oocyte maturation in the blue fox (Alopex lagopus). Anatomy and Embryology 181 325-331

Kalab P, Srsen V, Farstad W, Krogenaes A, Motlik J and Hafne A-L (1997) MAP kinase activation and RAF-1 synthesis in Blue fox oocytes is controlled by cumulus granulosa cells Theriogenology 47400 (Abstract)

Krogenaes A, Nagyova E, Farstad W and Hafne AL (1993) In vitro maturation of Blue fox oocytes and cAMP production in oocyte-cumulus cell complexes Theriogenology 39250 (Abstract)

Mahi CA and Yanagimachi R (1976) Maturation and sperm penetration of canine ovarian oocytes in vitro. Journal of Experimental Zoology 196 189-196

Mattioli M and Barboni B (2000) Signal transduction mechanism for LH in the cumulus-oocyte complex Molecular and Cellular Endocrinology 161 19-23

Metcalfe SS (1999) Assisted Reproduction in the Bitch MSc Thesis, Monash University

Nickson DA, Boyd JS, Eckersall PD, Ferguson JM, Harvey MJA and Renton JP (1993) Molecular biological methods for monitoring oocyte maturation and in vitro fertilization in bitches Journal of Reproduction and Fertility Supplement 47 231-240

Otoi T, Fujii M, Tanaka M, Ooka A and Suzuki T (1999) Effect of serum on the in vitro maturation of canine oocytes Reproduction, Fertility and Development 11 387-390

Otoi T, Fujii M, Tanaka M, Ooka A and Suzuki T (2000) Canine oocyte diameter in relation to meiotic competence and sperm penetration Theriogenology 54 535-542
Otoi T, Willingham L, Shin T, Kraemer DC and Westhusin M (2002) Effects of oocyte culture density on meiotic competence of canine oocytes Reproduction 124 775-781

Pearson OP and Enders RK (1943) Ovulation, maturation and fertilization in the fox Anatomical Record 85 69-83

Smith DM and Tenney DY (1980) Effects of steroids on mouse oocyte maturation in vitro. Journal of Reproduction and Fertility $60331-338$

Songsasen N, Yu I and Leibo SP (2002) Nuclear maturation of canine oocytes cultured in protein-free media Molecular Reproduction and Development 62 407-415

Srsen V, Kalous J, Nagyova E, Sutovsky P, King WA and Motlik J (1998) Effects of follicle-stimulating hormone, bovine somototrophin and okadaic acid on cumulus expansion and nuclear maturation of Blue fox (Alopex lagopus) oocytes in vitro. Zygote 6 299-309

Willingham-Rocky LA (2001) Supplementation of Canine Oocyte In Vitro Maturation Medium with Progesterone, Somatotropin, and Epidermal Growth Factor MSc Thesis, Texas A\&M University

Yamada S, Shimazu Y, Kawaji M, Nakazawa M, Naito K and Toyoda Y (1992) Maturation, fertilization and development of dog oocytes in vitro. Biology of Reproduction 46 853-858

Yamada S, Shimazu Y, Kawano Y, Nakazawa M, Naito K and Toyoda Y (1993) In vitro maturation and fertilization of preovulatory dog oocytes Journal of Reproduction and Fertility Supplement 47 227-229

Received 1 April 2003.

First decision 21 May 2003.

Revised manuscript received 17 June 2003.

Accepted 24 June 2003. 